\title{
Best Practice of Transformational Leadership among Multi- Ethnic Headteachers of Primary Schools, Malaysia
}

\author{
Asst Prof Dr Mohamad Johdi Salleh \& Parvina Saidova, MEd \\ International Islamic University Malaysia (IIUM)
}

\begin{abstract}
The objectives of this study are to examine the best practice of transformational leadership among multi-ethnic Headteachers of various types of primary schools, Malaysia, according to the gender, age, working experience, number of students, ethnic group, academic qualifications, working state, location of the school, and, type of school. The study was based on the survey of one-hundred-seventy-six multi-ethnic Headteachers pursuing a Bachelor of Educational Management programme who were chosen randomly and conveniently from three universities namely the University of Tun Hussein Onn Malaysia (UTHM), University of Malaysia Sabah (UMS), and International Islamic University Malaysia (IIUM). The findings are presented in frequency and percentage form. The result of the descriptive statistics showed that majority of the Multi-Ethnic Headteachers had a positive perception of practicing transformational leadership and they seemed to have an average level on their perception. This could mean that the school Headteachers had a positive attitude toward the importance of practicing all four dimensions of transformational leadership. Especially, the dimension of creating productive school culture was found significant. Noticeably, the dimension of providing intellectual stimulation was perceived least significant by respondents.
\end{abstract}

Keywords: Multi-Ethnic Headteachers Practice - Transformational Leadership

\section{Introduction}

The level of practice of transformational leadership in schools as it was perceived by Headteachers is an issue that needs to be studied. The self-evaluation of the Headteachers will raise the awareness and will determine their level of practice of transformational leadership which needs further investigation. It is these expressed concerns in the leadership of schools that brings one to question how far leadership in primary schools has moved away from the instructional and transactional models of leadership to the practice of transformational leadership style.

\section{Literature Review}

\subsection{Dimension of Transformational Leadership in School Settings}

Leithwood (1994) and his colleagues have provided fully developed model of transformational leadership especially for school setting. Their model is based on Burns (1978) and adapts Bass and Avolio's (1997) transformational leadership model to school settings. Leithwood conducted a research which concerned not only the nature of transformational school leadership but also the effects of such leadership on the school, teacher, and student outcomes. The results of Leithwood's studies into the nature of school leadership revealed specific dimensions of transformational school leadership and behaviors associated with each of these dimensions.

It is important to mention here that Leithwood's model of dimensions of transformational leadership in school settings is quite different from Bass and Avolio's (1997) model. However, the first three dimensions are similar to Bass and Avolio's (1997) model. One difference is that idealized influence (charisma) and inspirational motivation are treated as one dimension of transformational leadership in Leithwood's model. Leithwood (1994) conceptualized transformational leadership along with eight dimensions which are : (1) building school vision (developing a widely shared vision); (2) establishing school goals; (3) providing intellectual stimulation; (4) offering individualized support; (5) modeling best practices and important organizational values; (6) demonstrating high performance expectations; (7) creating a productive school culture; (8) developing structures to foster participation in school decisions.

More precisely, the following eight dimensions are grouped into three broad categories, namely, setting directions: building school vision; establishing school goals; demonstrating high performance expectations, developing people: providing intellectual stimulation; offering individualized support; modeling best practices and important organizational values; redesigning the organization: creating a productive school culture; and, developing structures to foster participation in school decision (Verona \& Young, 2001).

However, due to time and financial constraints, this study will use four dimensions in order to measure the level of practice of transformational leadership according to the Headteachers' perceptions. The four 
dimensions of transformational leadership were: (1) developing widely shared vision; (2) offering individualized support; (3) providing intellectual stimulation; and (4) creating productive school culture. In fact, these are the dominant factors of transformational leadership as briefly discussed in the following sections.

\subsection{Developing Widely Shared Vision}

Developing widely shared vision refers to the practices aimed at identifying new opportunities for the school and developing, articulating and inspiring others with a vision of the future (Mulfold, Silins and Leithwood, 2004). It is based on setting directions' category of Leithwood's and his colleagues' model (Leithwood, 1994 and Leithwood, Jantzi, \& Steinbech, 1999). They affirmed that vision is an "avenue of influence" in school improvement. In its broad meaning a vision enables one to see facets of school life that may otherwise be unclear, raising their importance above others. It is in fact an important element of leadership. Scholars in educational leadership suggest that vision may have an impact on schools. For example, the importance of vision on transformational model of school leadership was extensively studied by researchers such as Leithwood (1994) and Leithwood, Jantzi, \& Steinbech (1999). According to them a vision can also identify a path to a new future, a strategic dimension of leadership. They argue that it is the vision that assists the leaders in becoming a more effective problem solver by helping to sort and find the most important problems.

\subsection{Offering Individualized Support}

Offering individualized support refers to the practices that include respect for individual members of staff and concern about their personal feelings and needs (Mulfold, Silins \& Leithwood, 2004). Yu, Leithwood \& Jantzi (2002:374) also agrees with Mulfold's definition of offering individualized support and state that offering individualized support is:

Indications of respect for staff and concern about their personal feelings and needs (e.g. verbal persuasion). This dimension is likely to influence context beliefs by assuring teachers that the problems likely to be encountered while changing their practices will be taken seriously by those in leadership roles and efforts will be made to help them through those problems.

Some studies were carried out to measure the behavior of the school leaders which includes the offering individualized support (dimension of transformational leadership). Among those studies the study of Geijsel, Sleegers and Van Der Berg (1999) which examined the nature of transformational leadership and its relation to teachers' changed practices within the context of Dutch large-scale innovation programme is noticeable to mention here. They present two qualitative studies and a survey. The survey took place in Dutch Agricultural Training Centers (ATCs). ATCs provide pre-vocational education and senior secondary vocational education in the area of agriculture. Each of the 18 ATCs in The Netherlands was asked to participate in this study. All teachers of the participating schools received the questionnaires from their superiors; 49 percent responded for a total of 1,249 teachers. The qualitative studies revealed three dimensions of transformational leadership: vision, individual consideration, and intellectual stimulation. Within the framework of the survey, these dimensions were further operationalized and explanatively related to teachers' concerns, teachers' learning activities and teachers' changed practices.

\subsection{Providing Intellectual Stimulation}

Providing intellectual stimulation refers to the practices that challenges staff to reexamine some of the assumptions about their work and to rethink how it can be performed (Mulfold, Silins \& Leithwood, 2004). Therefore Yu, Leithwood \& Jantzi (2002:374) suggest that the Challenges to staff to reexamine some of the assumptions about their work and to rethink how it can be performed (a type of feedback associated with verbal persuasion). Such stimulation seems likely to draw teachers' attention to discrepancies between current and desired practices and to understand the truly challenging nature of school change goals. To the extent that such stimulation creates perceptions of a dynamic and changing job for teachers, it should enhance emotional arousal processes.

Numerous studies were carried out to measure intellectual stimulation behavior of school leaders. One of the studies which require citing here is the study of Geijsel, Sleeger, Leithwood and Jantzi (2003) which was carried out in Canada and Netherland on transformational leadership effects on teachers' commitment and effort toward school reform. More precisely, their study examined the effects of transformational school leadership on the commitment of teachers to school reform and the effort they are willing to devote to such reform. Results of the Canadian and Dutch studies were then compared. The findings showed transformational leadership dimensions to affect both teachers' commitment and extra effort. The effects of the dimension intellectual stimulation appear to be significant in particular. The findings clearly indicated the importance of analyzing dimensions of transformational leadership for their separate effects on teacher commitment and extra effort 
within the context of educational reform. The results suggest that for leadership to have any effect on students at the instructor level, a dedication to giving instructors the freedom to express their individual beliefs and values must be in place before students can take advantage of an instructor's unique approach to leadership.

\subsection{Creating Productive School Culture}

Every school creates new identities and establishes unique school cultures. Deal and Peterson (1999) defined the school culture as the kind of the underlining set of norms, values, beliefs, rituals, and traditions that make up the unwritten rules of how to think, feel and act in an organization. They further explained that every organization has a conscious, predictable part of the rules and procedures and so forth, but the school's culture is often below the stream of consciousness and is really what affects how people interact in an organization. It is the unwritten rules about interaction and problem solving and decision-making. There are some cultural norms that affect school improvement extensively: namely, (1) Collegiality; (2) Experimentation; (3) High expectations; (4) Trust and confidence; (5) Tangible support; (6) Reaching out to the knowledge base; (7) Appreciation and recognition; (8) Caring, celebration, and humor; (9) Involvement in decision making; (10) Protection of what's important; (11) Traditions; (12) Honest, open communication.

Leithwood (1994) stated that transformational leaders practice the three fundamental goals which one of them is creating productive school culture. Creating a productive school culture refers to the practices encompasses behavior which encourages collaboration among staff and assists in creating a widely shared set of norms, values and beliefs with continues improvement of services for the students (Mulfold, Silins \& Leithwood, 2004). Yu, Leithwood \& Jantzi (2002) also agreed with this definition, however he and his colleges asserted that these behaviors contribute to teacher commitment through their influence on teachers' understanding of the goals being pursued by the school and the importance of those goals, by virtue of them being widely shared.

Liontos (1992) explains the creating productive school culture by giving example of staff members who often talk, observe, critique, and plan together. Norms of collective responsibility and continuous improvement encourage them to teach each other how to teach better. He further asserts that transformational leaders involve staff in collaborative goal setting, reduce teacher isolation, share leadership with others by delegating power, and actively communicate the school's norms and beliefs. Leithwood (1992) also suggests that the school leaders actively communicate the school's cultural norms, values and beliefs in their day-to-day interpersonal contacts and they also share power and responsibility with others through delegation of power to school improvement teams.

Although transformational leadership has been identified as one of the most effective factor associating with school competency and Headteachers are always seen as transformational leaders in successful schools, yet there is less evidence on practicing transformational leadership effectively. In order to examine the Headteachers' involvement as transformational leaders this research aims to investigate Headteachers' perception of practicing of transformational leadership.

\subsection{Objective of the Study}

\section{Research Methodology}

The main purpose of this study is to examine the Headteachers' perception of practicing of transformational leadership. More precisely, the objectives of the study were: (1) to investigate the perception of Headteachers' of practicing of transformational leadership; (2) to find out to what extend the Headteachers' practice transformational leadership; (3) to examine the statistical differences in perception of Headteachers' of practicing of transformational leadership according to gender, age, ethnic group, academic qualifications, working experience, location of the school, type of school, school's grade and number of students.

\subsection{Sample of the Study}

The sample of the study were one-hundred-seventy-six PKPGB (Program Khas Pensiswazahan Guru Besar - Special Program of Bachelor of Educational Management for Headteachers) Headteachers from three selected universities which were the International Islamic University Malaysia (IIUM), University Tun Hussein Onn Malaysia (UTHM); University Malaysia, Sabah (UMS).

\subsection{Instrument}

A survey was conducted based on a questionnaire which consisted of 20 items. Questionnaire checklist was divided into two sections: Section 1: Comprised of demographic information of the respondents. The demographic variables of this study comprised of gender, age, working experience, number of students, ethnic group, academic qualifications, working state, location of the school, and, type of school. Section 2: Comprised of the items based on four dimensions of transformational leadership. The dimensions were: (1) developing 
widely shared vision; (2) providing intellectual stimulation; (3) offering individualized support; and (4) creating a productive school culture.

\subsection{Data Collection Procedure}

For the purpose of the study the researcher obtained an approval letter from the authority of every University. The questionnaires were distributed to the respondents with the help of Assoc Prof Dr. Baharom Mohamad (UTHM), Assoc Prof Dr. Mohd Yusof Abdullah (UMS), and Asst Prof Dr. Mohamad Johdi Salleh (IIUM). All participants' responses were voluntary selected. The questionnaire with its twenty items which comprised of transformational leadership measuring four dimensions was administrated. Response choices was ranged from 1 to 5 (not at all) to five (frequently, if not always).

\subsection{Analysis of Data}

Statistical analysis was conducted to examine the practice of transformational leadership among Headteachers of primary schools, Malaysia, according to the gender, age, working experience, number of students, ethnic group, academic qualifications, working state, location of the school, and, type of school. Descriptive statistics was used by using the Statistical Package for Social Sciences (SPSS, version 17) programme. The numbers of items measuring each variable were based on four dimensions of transformational leadership, namely, developing widely shared vision; providing intellectual stimulation; offering individualized support; and, creating productive school culture.

\section{Analysis And Findings}

\subsection{Headteachers' Perception of Practicing of Transformational Leadership}

Table 4.1 illustrates the perceptions of Headteachers of practicing of transformational leadership. The perceptions are presented in frequency and percentage form.

The score of the items indicate that a majority of the Headteachers practiced transformational leadership fairly often. Looking at each item, the least item in practicing transformational leadership under the category "fairly often" was item 7: "I communicate school mission and vision to staff" which scored $35.8 \%$. However, the highest item scored under category "fairly often" was item 18 which scored $63.1 \%$. It illustrates "I symbolize success and accomplishment within staff profession". Under the category "frequently" the least item scored $20.5 \%$ which was item 1: "I use reasoning and evidence rather than unsupported opinion". The highest item scored $54.5 \%$ which was the item 13: "I provide moral support by making staff feel appreciated". Three items (1, 2 and 4) have the highest score under the category of "sometimes". The item second scored $30.7 \%$ which was "I get staff to rethink ideas they had never questioned before". Item number 1 scored $25.6 \%$ which was "I use reasoning and evidence rather than unsupported opinion". Lastly item 4 scored 19.9\% which was "I encourage staff to try new practices consistent with their interests".

These results illustrate that majority of Headteachers practice transformational leadership fairly often. However, most of them do practice transformational leadership frequently. The items presented on Table 1 shows that some of Headteachers practice transformational leadership sometimes. The scores of the items under category "fairly often" and "frequently" have similarities.

Table 1: Summary of Respondents' Perception of Practicing Transformational Leadership

\begin{tabular}{|c|c|c|c|c|}
\hline \multirow{2}{*}{\multicolumn{2}{|c|}{ Items }} & $\mathbf{S}$ & FO & $\mathbf{F}$ \\
\hline & & (n) & (n) & (n) \\
\hline \multicolumn{5}{|c|}{ Providing Intellectual Stimulation } \\
\hline 1. & $\begin{array}{l}\text { I use reasoning and evidence rather than } \\
\text { unsupported opinion }\end{array}$ & $25.6 \%(45)$ & $51.1 \%(90)$ & $20.5 \%(36)$ \\
\hline 2. & $\begin{array}{l}\text { I get staff to rethink ideas they had never } \\
\text { questioned before }\end{array}$ & $30.7 \%(54)$ & $50.0 \%(88)$ & $13.6 \%(24)$ \\
\hline 3. & $\begin{array}{l}\text { I facilitate opportunities for staff to learn from each } \\
\text { other }\end{array}$ & $12.5 \%(22)$ & $51.1 \%(90)$ & $33.0 \%(58)$ \\
\hline 4. & $\begin{array}{l}\text { I encourage staff to try new practices consistent } \\
\text { with their interests }\end{array}$ & $19.9 \%(35)$ & $52.3 \%(92)$ & $26.7 \%(47)$ \\
\hline \multirow[t]{2}{*}{5 . } & $\begin{array}{l}\text { I encourage staff to pursue their own goals for } \\
\text { professional learning }\end{array}$ & $11.9 \%(21)$ & $48.9 \%(86)$ & $38.1 \%(67)$ \\
\hline & \multicolumn{4}{|l|}{ Developing Widely Shared Vision } \\
\hline 6. & I give staff a sense of overall purposes & $13.6 \%(24)$ & $52.3 \%(92)$ & $31.8 \%(56)$ \\
\hline 7. & I communicate school mission and vision to staff & $13.6 \%(24)$ & $35.8 \%(63)$ & $50.0 \%(88)$ \\
\hline 8. & $\begin{array}{l}\text { I talk enthusiastically about what needs to be } \\
\text { accomplished }\end{array}$ & $10.8 \%(19)$ & $54.5 \%(96)$ & $33.0 \%(58)$ \\
\hline
\end{tabular}


9. I work toward whole staff agreement in establishing $4.0 \%(7)$ priorities for school goals

10. I express confidence that goals will be achieved

\section{Offering Individualized Support} initiating actions

12. I treat staff as individuals rather than just a member of a group

13. I provide moral support by making staff feel appreciated

14. I consider staff as individual having different needs, $11.9 \%$ (21) abilities and aspiration from others

15. I help staff to develop their strengths

\section{Creating Productive School Culture} 16. I encourage the development of a strong school
culture

17. I set respectful tone for interaction with staff

18. I symbolize success and accomplishment within staff profession

19. I show respect for staff by treating them as $5.7 \%(10)$ professionals

20. I promote an atmosphere of caring and trust among $5.7 \%(10)$ staff

Note: $\mathrm{S}=$ sometimes, $\mathrm{FO}=$ fairly often, $\mathrm{F}=$ frequently

More precisely, the items which got highest mean score according to Headteachers' view on practicing transformational leadership were under the three dimensions of transformational leadership: (1) developing widely shared vision; (2) offering individualized support; and (3) creating productive school culture. The least dimension scored was providing intellectual stimulation. This means, the highest dimension scored was creating productive school culture and the least dimension scored was the dimension of providing intellectual stimulation.

\subsection{Practicing of Transformational Leadership and Demographic Variables: Practice and Gender}

In order to examine the perceptions of Headteachers of practicing transformational leadership according to gender the T-test was employed shown on Table 2.

Table 2: Respondents' Perception of Practice and Gender

\begin{tabular}{ccccc}
\hline Gender & M & SD & t-value & P \\
\hline Male & 82.47 & 8.08 & 4.769 & .000 \\
Female & 88.27 & 6.96 & & \\
\hline
\end{tabular}

Table 2 shows the result of the T-test analyses illustrates that there was a significant difference in perceptions of Headteachers of practicing transformational leadership between male and female, $t=4.769, \mathrm{p}<.000$.

\subsection{Practice, Age, Working Experience and Number of Students}

Table 3 shows that there was a significant correlation between the age of headteachers and practicing of four dimensions of transformational leadership $(\mathrm{r}=.168, \mathrm{p}<.026)$.

Table 3: Relationship between Practice, Age, Working Experience, Number of Students

\begin{tabular}{lc}
\hline \multicolumn{1}{c}{ Demographics } & Correlation $(\mathbf{r})$ \\
\hline Age & $.168^{*}$ \\
Working Experience & $.196^{* *}$ \\
Number of Students & $.164^{*}$ \\
\hline Notice: (r) = Pearson Correlation. * Correlation is significant at $\mathrm{p}<0.05$ level. $* *$ Correlation is significant at $\mathrm{p}<0.01$.
\end{tabular}

The table shows that there was a significant positive relationship between working experience of the respondents and practicing of four dimensions of transformational leadership $(r=.196, p<.009)$. According to the number of students and practicing four dimensions of transformational leadership Pearson correlation indicates 
that there was a positive significant correlation $(r=.164, p<.030)$ between number of students in a school and the practice of four dimensions of transformational leadership as it was perceived by Headteachers. This means that there was a positive significant relationship between the age, working experience, number of students in the school and practice of four dimensions of transformational leadership.

\subsection{Practice, Ethnic Group, Academic Qualifications, Location \& Type of School and Schools Grade}

Table 4 shows the One- Way ANOVA of Respondents' Perception on Practice, Ethnic Group Academic Qualifications, Location of the School, Type of the School and Schools' Grade.

One-Way ANOVA was employed to investigate if there was a significant difference in respondents' perception of practice according to Ethnic group, Academic qualifications, Location of the school, Type of the school and Schools' grade.

The results on Table 4 shows that there was a positive significant difference of respondents' perceptions of practice according to Ethnic group (F=7.050, p> .000) and practice. Similarly, the result shows that there was a positive significant difference of respondents' perceptions of practice according to Location of the school $(\mathrm{F}=3.849, \mathrm{p}>$.023), Type of the school $(\mathrm{F}=3.576, \mathrm{p}>.015)$ and Schools' grade $(\mathrm{F}=3.432, \mathrm{p}>.035)$.

Table 4: One- Way ANOVA of Respondents' Perception on Practice, Ethnic Group, Academic Qualifications, Location of the School, Type of the School and Schools' Grade

\begin{tabular}{|c|c|c|c|c|}
\hline Demographics & Sum of Squares & Mean Square & $\mathbf{F}$ & Sig. \\
\hline Ethnic Group & & & 7.050 & .000 \\
\hline Between Groups & 1279.882 & 426.627 & & \\
\hline Within Groups & 10408.067 & 60.512 & & \\
\hline Academic Qualification & & & 2.172 & .074 \\
\hline Between Groups & 565.217 & 141.304 & & \\
\hline Within Groups & 11122.732 & 65.045 & & \\
\hline Location of the School & & & 3.849 & .023 \\
\hline Between Groups & 497.871 & 248.936 & & \\
\hline Within Groups & 11190.078 & 64.683 & & \\
\hline Type of the School & & & 3.576 & .015 \\
\hline Between Groups & 686.137 & 228.712 & & \\
\hline Within Groups & 11001.812 & 63.964 & & \\
\hline School's Grade & & & 3.432 & .035 \\
\hline Between Groups & 446.028 & 223.014 & & \\
\hline Within Groups & 11241.921 & 64.982 & & \\
\hline
\end{tabular}

Table 4 shows that there was a slight difference of Academic qualifications $(F=2.172, p>.074)$ and practice which was not significant.

Table 5 shows the result of the Pos Hoc Turkey (HSD) of Respondents Perceptions of Practice and Ethnic Group.

Table 5: Pos Hoc Turkey (HSD) of Respondents Perceptions of Practice and Ethnic Group

\begin{tabular}{cccc}
\hline Ethnic Group & Ethnic Group & Mean Difference & Sig. \\
\hline Malay & Chinese & -4.42 & .073 \\
& Indian & -3.17 & .725 \\
Chinese & Sabah and Sarawak & 3.91 & $.021^{*}$ \\
& Malay & 4.42 & .073 \\
& Indian & 1.24 & .982 \\
Indian & Sabah and Sarawak & 8.33 & $.000^{*}$ \\
& Malay & 3.17 & .725 \\
& Chinese & -1.24 & .982 \\
Others & Sabah and Sarawak & 7.08 & .111 \\
& Malay & -3.91 & $.021 *$ \\
& Chinese & -8.33 & $.000^{*}$ \\
& Indian & -7.08 & .111 \\
\hline
\end{tabular}

Table. 5 shows the result indicated that there is a significant difference between Malays and (mean $=3.91$, $\mathrm{p}<.021$ ), Sabah and Sarawak ethnic groups and Chinese (mean=8.33, $\mathrm{p}<.000)$. 
Table 6 shows the result of the Pos Hoc Turkey (HSD) of respondents' perceptions of practice and Type of School.

Table 6: Pos Hoc Turkey (HSD) of Respondents' Perceptions of Practice and Type of School

\begin{tabular}{cccc}
\hline & & Mean & \\
Type of School & Type of School & Difference & Sig. \\
\hline National & Chinese & -5.36 & $.024^{*}$ \\
& Tamil & -4.24 & .581 \\
Chinese & Ex-missionary/English & -5.00 & .516 \\
& National & 5.36 & $.024^{*}$ \\
& Tamil & 1.11 & .990 \\
Tamil & Ex-missionary/English & .352 & 1.000 \\
& National & 4.24 & .581 \\
& Chinese & -1.11 & .990 \\
Ex-missionary/English & Ex-missionary/English & -.76 & .999 \\
& National & 5.00 & .516 \\
& Chinese & -.35 & 1.000 \\
& Tamil & .76 & .999 \\
\hline The mean difference is significant at the 05 level
\end{tabular}

The results on table 6 indicated that there is a significant difference between National and Chinese (mean $=-5.36$, $\mathrm{p}<.024)$ schools.

Table 7 shows the Pos Hoc Turkey (HSD) of respondents' perceptions of practice and location of the school.

Table 7: Pos Hoc Turkey (HSD) of Respondents Perceptions of Practice and Location of the School

\begin{tabular}{cccc} 
School's Location & School's Location & Mean Difference & Sig. \\
\hline Urban & Rural & 2.51 & .174 \\
& Remote & 4.88 & $.019^{*}$ \\
\multirow{2}{*}{ Rural } & Urban & -2.51 & .174 \\
& Remote & 2.37 & .317 \\
\multirow{2}{*}{ Remote } & Urban & -4.88 & $.019^{*}$ \\
& Rural & -2.37 & .317 \\
\hline
\end{tabular}

* The mean difference is significant at the .05 level.

The result on table 7 indicated that there is a difference between schools location in Urban and Remote areas $($ mean $=4.8, \mathrm{p}<.019)$.

\section{Discussion Of The Findings \\ 5.1 Practice and Dimensions of Transformational Leadership}

The consistency of the present results with its general findings is promising in view of the benefits of transformational leadership. The result of the descriptive statistics showed that majority of Headteachers had a positive perception of practicing transformational leadership and they seemed to have an average level on their perception. This could mean that the school Headteachers had a positive attitude toward the importance of practicing of four dimensions of transformational leadership. Especially, the dimension of creating productive school culture was found significant. Noticeably, the dimension of providing intellectual stimulation was perceived least significant by respondents.

This finding contradicts with the findings of the study done by Giejsel, Sleegers, Leithwood \& Jantzi (2003) in Netherlands and Canada which revealed that providing intellectual stimulation appear to be the most significant dimensions of transformational leadership in school. However, the result of this study confirmed the study of Geijsel et al. (2003) where the dimension of developing shared vision was found significant.

The results of the descriptive statistics showed that the respondents perceived themselves to practice the four dimensions of transformational leadership on an average level. The Headteachers evaluated themselves very high in creating productive school culture and developing widely shared vision. 


\subsection{Practice and Demographic Variables}

The question number three was about finding any statistically significant difference in perception of Headteachers of practicing transformational leadership according to their gender, age, ethnic group, academic qualifications, working experience, location of the school, type of school, school's grade and number of students. The result of the $t$-test analysis showed that there was a significant difference between male and female Headteachers in their perception of practicing transformational leadership. From the findings of the study, it became obvious that female Headteachers rated themselves as more transformational than the male Headteacher. This finding is consistent with three studies reported by Bass et al., (1996) in which female managers were more likely to be rated by their followers as transformational than were their male counterparts. The woman leaders attained higher scores for all four dimensions of leadership: charisma, inspirational motivation, intellectual stimulation and individualized consideration.

The result of one-way ANOVA reported that there was a significant difference in the perception of Headteachers according to Ethnic group. The Sabah and Sarawak ethnic groups rated themselves to practice more transformational leadership as compared to Malay and Chinese ethnic groups. The study also found that there was a significant difference in the perception of Headteachers according to Type and Location of the school. The Headteachers of Chinese schools rated themselves to practice more often transformational leadership as compared to National schools. Ironically, the Headteachers whose schools are located at remote areas rated they practice more often the four dimensions of transformational leadership as compared to Headteachers whose schools are located at urban areas. The result of Pearson Correlation $(r)$ indicated that there was a significant correlation between practice and age of the Headteachers practice and number of students under each Headteacher's supervision.

\section{Conclusion}

In light of these surprising findings, the PKPGB (Program Khas Pensiswazahan Guru Besar) students of International Islamic University Malaysia (IIUM), Universiti Tun Hussein Onn Malaysia (UTHM) and Universiti Malaysia, Sabah (UMS) rated themselves to practice the four dimensions of transformational leadership on an average level. The female Headteachers seemed to have more transformational behaviors as compare to male Headteachers. This is the kind confidence that the female Headteachers rated themselves as transformational leaders. These findings contradicted the previous researchers' findings such as Manning (2002). Nevertheless, the findings of this study confirmed the findings of Burke and Collins (2001), Carless (1998) Bass et al., (1996) studies where their findings reported that there was a significant difference between male and female in practicing transformational leadership. Therefore, the findings of this study suggest that the women are more transformational leaders than the men regardless of any type of organizations school or non school settings. The Headteachers who practiced the potential four dimensions of transformational leadership realized that they stimulate staff's' professional learning, foster staff's' intellectual curiosity and the most important facilitate the vision for the school.

\section{References}

[1]. Amoroso, P.F. (2002). The impact of principals' transformational leadership behaviors on teacher commitment and teacher job satisfaction. Unpublished doctoral dissertation, NJ: Seton Hall University, South Orange

[2]. Avolio, B.J. and Bass, B.M. (2002). Developing potential across a full range of leadership cases on transactional and transformational leadership. NJ: Lawrence Erlbaum Associates, Mahwah.

[3]. Bass, B. and Avolio, B. (1997). The full range leadership development manual for the multifactor leadership questionnaire. Redwood City, CA: Mind Garden,

[4]. Burke, Sarah., \& Collins, M. K. (2001). Gender differences in leadership styles and management skills. Women in Management Review, 16 (5), 244-257.

[5]. Burns, J.M. (1978). Leadership. NY: Harper \& Row.

[6]. Bush, T., \& Glover, D. (2003). School leadership: Concepts and evidence. Nottingham, England: National College for School Leadership.

[7]. Carles, A. S (1998). Gender Differences in Transformational Leadership: An Examination of Superior, Leader, and Subordinate Perspectives. Sex Roles, 39, 11-12, 887-900.

[8]. Creswell, W.(2002). Educational research: Planning, conducting and evaluating quantitative and qualitative research. Upper Saddle River, NJ: Merrill Prentice Hall.

[9]. Deal, T. E., \& Peterson, K. D. (1999). Shaping school culture: The heart of leadership. San Francisco:

[10]. Geijsel, F., Sleegers, P., Leithwood, K., \& Jantzi, D. (2003). Transformational leadership effects on teachers' commitment and effort toward school reform. Journal of Educational Administration, 41 (3), 228-256. Retrieved April 8, 2009, from http://www.emeraldinsight.com/0957-8234.htm

[11]. Geijsel, F., Sleegers, P., \& Berg, R. van den. (1999). Transformational leadership and the implementation of large-scale innovation programs. Journal of Educational Administration, 37 (4), 309-328.

[12]. Hallinger, P., \& Murphy, J. (1987). Assessing and developing principal instructional leadership. Educational Leadership, 45(1), 5461.

[13]. Hatchet, M. E. (2002). An analysis of teacher empowerment, transformational leadership and job satisfaction in the elementary school. Michigan: ProQuest Company.

[14]. Leithwood K.A. (1992). Transformational Leadership: Where does it stand? The Education Digest, 58(3), 17-20.

[15]. Leithwood, K.A. (1994). Leadership for Restructuring. Educational Administration Quarterly, 30, 498-518 
[16]. Leithwood, K., Jantzi, D. (1999). The effects of transformational leadership on organizational conditions and student engagement with school. Paper presented at the meeting of the American Educational Research Association. Montreal: Canada.

[17]. Leithwood, K., Jantzi, D. \& Steinbech, R. (1999). Changing Leadership for Changing Times. Open University Press, Buckingham, Philadelphia, PA.

[18]. Leithwood, K., \& C, Riehl. (2003). What we know about successful school leadership. Philadelphia, PA: Laboratory for Student Success. Temple University.

[19]. Leithwood, K., \& Jantzi Doris (2005). Transformational leadership. In Davies, Brent (Ed.), The essentials of school leadership (pp31-41). Sage Publications, Thousand Oaks, CA.

[20]. Liontos, L. B. (1992). Transformational leadership. Educational Management, Clearing House, 72 (4), 192. (ERIC Journal No. ED347636)

[21]. Lunenburg, F. C. (2003). Emerging perspectives: The usefulness of the construct of transformational Leadership in Educational Organizations. Paper presented at the Annual Meeting of the national Council of Professors of Educational Administrations. Sedona. Az.

[22]. Manning, T. Tracey (2002). Gender, managerial level, transformational leadership and work satisfaction. Women in Management Review, 17, (5), 207-216.

[23]. Mills, J. M. (2008). Leadership and school reform: The effects of transformational leadership on Missouri Assessments. Unpublished doctorial dissertation, Capella University.

[24]. Mulford, B. W, Silins, H., \& Leithwood, K. (2004). Educational leadership for organizational learning and improved student outcomes. Dordrecht. The Netherlands: Kluwer Academic Publisher.

[25]. Sashkin, M., \& Rosenbach, E.W. (1992). Assessing transformational leadership and its impact. Greensboro, NC: Center for Creative Leadership.

[26]. Verona, S. G., \& Young, W.J. (2001). The influence of principal transformational leadership style on high school proficiency test results in New Jersey comprehensive and vocational-technical high schools. Paper Presented At The Annual Meeting Of The American Educational Research Association. Seattle, WA.

[27]. Yu, H., Leithwood, K., \& Jantzi, D. (2002). The effects of transformational leadership on teachers' commitment to change in Hong Kong. Journal of Educational Administration, 40, 368-389.

[28]. Yukl, G. (2006). Leadership in organizations. (6 ${ }^{\text {th }}$ edn.). New Jersey: Pearson Prentice Hall. 